\title{
Influencia de la disminución de lodo para la obtención de voltaje a partir de Celdas de Combustible Microbianas de bajo costo
}

\author{
${ }^{1}$ Segundo J. Rojas Flores, ${ }^{2}$ Luis M. Angelats Silva, ${ }^{1}$ Magaly De La Cruz Noriega, 'Mayli Jazmín León \\ Castañeda, ${ }^{1}$ Royer Gonzales Rubio, ${ }^{1}$ Lucero Joo Jim, ${ }^{1}$ Magda R. Rodriguez Yupanqui. \\ 1 Universidad Privada Cesar Vallejo, Av. Larco 1771, Víctor Larco Herrera, Trujillo, Perú \\ 2 Universidad Privada Antenor Orrego, Laboratorio de Investigación Multidisciplinaria, Av. América Sur 3145, \\ Trujillo, Perú
}

Recibido el 8 de noviembre del 2018. Revisado el 8 de diciembre del 2018. Aceptado el 10 de diciembre del 2018.

DOI: https://doi.org/10.33017/RevECIPeru2018.0014/

\section{Resumen}

Recientemente, se ha puesto gran atención a las celdas de combustible microbianas (CCM) debido a sus condiciones de operación moderadas y al uso de una variedad de sustratos biodegradables como combustible. Las celdas de combustible microbianas comunes consisten en una cámara anódica y una cámara catódica separadas por una membrana de intercambio protónico. Los microorganismos catabolizan activamente el sustrato generando bioelectricidad. Estas celdas se pueden utilizar como un generador de energía para biosensores, dando con esto una gran ventaja para aplicación en estos tipos de dispositivos. En este trabajo se presenta cedas de combustible microbianas, diseñadas a bajo costo, en las cuales se ha variado la concentración de lodo, el cual fue obtenido de las lagunas de oxidación de Covicorti, Trujillo- La Libertad. Los valores del voltaje promedio fueron reduciendo a medida que disminuye la concentración del lodo, desde valores cercanos a 507.8 a $244.1 \mathrm{mV}$. La conductividad en la cámara anódica estuvo alrededor de 14,5 a 7,75 $\mu \mathrm{S} / \mathrm{cm}$ con un $\mathrm{pH}$ alrededor de 8,0. Mientras que en la carama catódica se encontró un pH alrededor de 7,5 y una turbidez entre 250 a 450 UNT; los valores de la intensidad de corriente y densidad de potencia también disminuyen con la disminución de lodo residual. Con este trabajó se trata de dar una nueva forma de fabricación de CCM de manera innovadora y económica.

Descriptores: Celdas de combustible microbianas, microorganismos, ánodo, cátodo y voltaje.

\section{Abstract}

Recently, great attention has been given to microbial fuel cells (CCM) due to their moderate operating conditions and the use of a variety of biodegradable substrates as fuel. The common microbial fuel cells consist of an anodic chamber and a cathode chamber separated by a proton exchange membrane. The microorganisms actively catabolize the substrate generating bioelectricity. These cells can be used as an energy generator for biosensors, giving this a great advantage for application in these types of devices. This paper presents microbial fuel lines, designed at low cost, in which the concentration of sludge has been varied, which was obtained from the oxidation lagoons of Covicorti, Trujillo-La Libertad. The values of the average voltage were reduced as the concentration of the mud decreases, from values close to 507.8 to $244.1 \mathrm{mV}$. The conductivity in the anodic chamber was around 14.5 to $7.75 \mu \mathrm{S} / \mathrm{cm}$ with a pH around 8.0. While in the cathodic carame a pH around 7.5 and a turbidity between 250 to 450 NTU was found, the values of current intensity and power density also decrease with the reduction of residual sludge. With this work, it is about giving a new way of manufacturing CCM in an innovative and economical way.

Keywords: Microbial fuel cells, microorganisms, anode, cathode and voltage. 


\section{Introducción}

En los últimos años los científicos han comenzado a intensificar los esfuerzos en la búsqueda de nuevos sistemas de producción de electricidad de forma económica y amigable con la naturaleza, más aún en zonas rurales. En los Países Bajos y la India se ha logrado producir electricidad a base de plantas vivas, dando con ello una nueva alternativa decorativa y económica para los jardines de las familias $[1,2]$. En el estudio de la producción de electricidad a partir de plantas vivas, se ha logrado encontrar que la electricidad generada provenía de las bacterias existentes en el suelo. Estas bacterias, al hacer contacto con los electrodos, permitía el flujo de electrones libres $[3,4]$. Si la electricidad se produce debido a las bacterias, entonces se ha logrado diseñar un dispositivo llamado celda de combustible microbiana (MCC), este dispositivo convierte directamente la potencia metabólica microbiana en electricidad usando tecnología electroquímica. La energía química se convierte en energía eléctrica mediante el acoplamiento de la oxidación biodegradativa de sustratos orgánicos 0 inorgánicos a la reducción química de un oxidante en la interfaz entre el ánodo y el cátodo. La transferencia directa de electrones de las celdas microbianas a los electrodos se ha producido con baja eficiencia. En celdas de combustible microbianas, se requieren dos parejas redox. El primero acopla la reducción de electrones al metabolismo oxidativo bacteriano. El segundo acopla la oxidación del mediador de electrones a la reducción del aceptor de electrones en la superficie del cátodo, donde el aceptor de electrones se regenera con oxígeno atmosférico [5].

La generación de energía y la eliminación de residuos son dos desafíos claves en la búsqueda de sociedades sostenibles. Las CCM en principio, proporciona una solución viable al vincular ambas tareas. La celda de combustible microbiana utiliza microorganismos activos como biocatalizador en un compartimento de ánodo anaeróbico para la producción de bioelectricidad. Aunque Potter observó la corriente eléctrica producida por las bacterias en 1911, a principios de la década de 1990, las CCM se convirtieron en dispositivos mucho más atractivos; en consecuencia, las CCM se consideraron como tecnología prometedora. La investigación de las CCM se volvió mucho más llamativa en 1999 una vez que se descubrió que el mediador no era un componente obligatorio dentro de los CCM. Teniendo en cuenta que las aguas residuales municipales 0 domésticas contienen grandes cantidades de desechos orgánicos biodegradables, tales dispositivos tendrían el potencial de producir electricidad de las plantas de tratamiento de aguas residuales. Estos dispositivos también pueden ser potencialmente utilizados para la recuperación de metales y nutrientes de efluentes industriales [5,6].

En la actualidad se ha logrado implementar tres diseños diferentes de celdas de combustible microbianas (tipos $A, B$ y $C$ ), con diversos grados de éxito. En las celdas de combustible tipo $A$, los mediadores redox artificiales capaces de penetrar células bacterianas se agregan a la solución de cultivo dentro del compartimiento de la celda de combustible anódico, lo que permite que los electrones producidos durante la fermentación u otros procesos metabólicos sean transportados al ánodo. Las celdas de combustible tipo $\mathrm{B}$ incorporan bacterias reductoras de metales (por ejemplo, miembros de las Geobacteraceae y Shewanellaceae) que exhiben parcialmente citocromos especiales unidos a la membrana capaces de transferir electrones directamente a los electrodos (en lugar de disuelto o hierro sólido (III) o manganeso (IV/III)). Y las celdas de combustible de tipo $\mathrm{C}$ oxidan los productos de fermentación, como el hidrógeno y el metanol, en electrodos electrocatalíticos (es decir, electrodos modificados químicamente capaces de oxidar eficientemente tales metabolitos); estas últimas reacciones a menudo se inhiben en la superficie de los electrodos de oro, platino o carbono. Los tres diseños tienen su parte de ventajas y desventajas [14].

Las celdas de combustible tipo A muestran densidades de corriente bastante buenas, pero tienen la necesidad de usar mediadores redox sintéticos ya que deben agregarse al cultivo y no son recuperables. Las celdas de combustible tipo $B$ pueden funcionar en ambientes naturales (por ejemplo, sedimentos); sin embargo, la tasa de crecimiento de las bacterias $\mathrm{y}$, por lo tanto, las densidades de corriente generadas son muy bajas. $Y$ aunque las celdas de combustible tipo $C$ producen las densidades de corriente más altas y funcionan con microorganismos simples y fácilmente disponibles (por ejemplo, Escherichia coli), los electrodos electrocatalíticos requieren modificadores de superficie bastante costosos que dificultan la implementación. Las celdas de combustible microbianas pueden ofrecer un tratamiento biológico de contaminantes orgánicos 
de aguas residuales salinas al mismo tiempo que producen electricidad, lo que representa una gran oportunidad para mitigar los impactos ambientales y recuperar recursos de manera rentable $[7,10]$. Las CCMs producen electricidad mientras tratan las aguas residuales a través de bacterias que pueden oxidar compuestos orgánicos (es decir, donantes de electrones) en condiciones anaeróbicas mientras usan un aceptor de electrones terminal sólido en el proceso (por ejemplo, electrodos de zinc) [8].

Estudios anteriores informaron que el poder reductor metabólico producido por Escherichia coli - Proteus vulgaris se convirtió en electricidad mediante el uso de mediadores como la 2-hidroxi1,4-naftoquinona. Muchas especies bacterianas diferentes, incluyendo Escherichia, Shewanella, Clostridium y Desulfovibrio, reducen los iones metálicos (por ejemplo, manganeso, férrico, uranio y cúprico) mientras oxidan los sustratos orgánicos [8-9].

Recientemente se ha demostrado que una variedad de microbios son electrofílicos. Ahora también se sabe que la metabolización de los metanógenos puede crecer con la electricidad (es decir, el cátodo) como donante de electrones al tiempo que reduce el $\mathrm{CO}_{2}$ como aceptador de electrones. Kim et al (1999) demostraron recientemente que Shewanella putrefaciens, tiene citocromos que contienen hierro en su membrana externa, puede crecer utilizando lactato como donador de electrones y un ánodo de grafito como aceptor de electrones. Las reacciones químicas llevadas a cabo durante el funcionamiento de la CCM, son muy complejas dado que en el lodo o las aguas residuales hay muchas bacterias 0 componentes juntos, el oxígeno e iones positivos en el ánodo participan en la siguiente reacción para formar agua que se propaga a través de la membrana permeable a los iones en el cátodo junto con la asistencia de catalizadores de la siguiente manera [9]:

$$
\begin{gathered}
\mathrm{H}_{2}->2 \mathrm{H}^{+}+2 e^{-} \\
\mathrm{O}_{2}+4 \mathrm{H}^{+}+4 e^{-}->2 \mathrm{H}_{2} \mathrm{O}
\end{gathered}
$$

La concentración y las especies en el oxidante (aceptor de electrones), la disponibilidad de protones, el rendimiento del catalizador, la estructura del electrodo y su capacidad catalítica afectan el rendimiento de reacción del cátodo [10].

La generación de energía y la eliminación de residuos, son dos desafíos clave en la búsqueda de sociedades sostenibles. Las celdas de combustible electroquímicas pueden, en principio, proporcionar una solución elegante al vincular ambas tareas. Debido a esto se diseñó una biocelda para demostrar que el uso de residuos orgánicos (como la cáscara de papa), pueden ser utilizados como carburantes para alimentar las celdas y de esta manera promover el potencial recuperable y económico de la biomasa, además de contribuir a disminuir los problemas que afronta la sociedad actual: El aumento de residuos sólidos y la crisis energética. Los resultados comparativos de dicho tratamiento permitieron determinar la cantidad de energía generada en cada tratamiento [11].

Debido al no aprovechamiento de los residuos generados por la sociedad, este estudio da una alternativa para su aprovechamiento generando voltaje mediante la utilización de celdas microbianas diseñadas a bajo costo. Con este alternativa se pretende que la sociedad y el estado se de cuenta que se puede aprovechar los desechos de una comunidad para su propio beneficio.

\section{Metodología}

Se usó tapers herméticos de $15 \times 15 \times 20 \mathrm{~cm}^{3}$ para la fabricación de 5 celdas (cada una con cámara anódica y catódica), en los cuales se realizaron orificios circulares de $2,5 \mathrm{~cm}$ de diámetro en la parte lateral para poder colocar la membrana de intercambio. En la parte superior del taper se realizó orificios circulares de $1 \mathrm{~cm}$ de diámetro para la salida del cable conductor que salía del ánodo y del cátodo respetivamente. En el cámara catódica, se realizó un orifico para la entrada de $\mathrm{O}_{2}$ mediante una pequeña bomba de aire. Membrana: Se usó soga driza de $20 \mathrm{~cm}$ de largo y $1 \mathrm{~cm}$ de diámetro, la cual se envolvió con cinta aislante (negra) perfectamente para disminuir el contacto del ambiente con la membrana y el intercambio solo se realice entre las cámaras del ánodo y cátodo. Para el ánodo, se usó cobre electrolítico (Cu-ETP) de $10 \times 10 \mathrm{~cm}$ y $0,2 \mathrm{~cm}$ de grosor. Mientras que, para el cátodo, se usó placas de Zinc (BLAC A36) de $10 \times 10 \mathrm{~cm}$ y 0,2 de grosor.

\subsection{Recolección de Muestra}

El lodo que se utilizó para la investigación fue recolectado de las lagunas de oxidación de covicorti, Trujillo, La Libertad. Se usó 10 litros de lodo, la cual se repartió en diferentes concentraciones. El lodo se repartió en celdas microbianas variando su concentración, desde un 100 al 50 por ciento, para poder observar el efecto que este tenía en la producción de voltaje, corriente, densidad de potencia, conductividad y $\mathrm{pH}$. Esto se 
logró con ayuda del laboratorio de biotecnología de la Universidad Cesar Vallejo y el laboratorio de Investigación Multidisciplinaria de la Universidad Privada Antenor Orrego

\subsection{Construcción de la Celda de combustible Microbiana}

Se construyó un prototipo de celda de combustible microbiana (CCM), que consto de dos cámaras de plástico (catódica y anódica), de forma rectangular y una membrana de intercambio catiónica con el cual se obtenía el voltaje como se esquematiza en la figura 1. En el ánodo se colocó el lodo (bacterias), esta cámara estaba totalmente sellada debido a las tabas de los plásticos estaban sujetadas a presión y la membrana estaba perfectamente sellada con ayuda de silicona líquida. En la otra recamara se colocó agua destilada con $\mathrm{NaCl}$ al $5 \%$ y pH 7 . Se trabajó con volúmenes de agua con sal constante, la variable a estudiar fue el nivel de contracción del lodo en la cámara del ánodo, las cual fue disminuyendo desde un 100 hasta $50 \%$.

\section{Resultados y Discusión}

En la figura 2 se muestra los resultados obtenidos de las 5 celdas de combustible microbianas construidas a bajo costo.

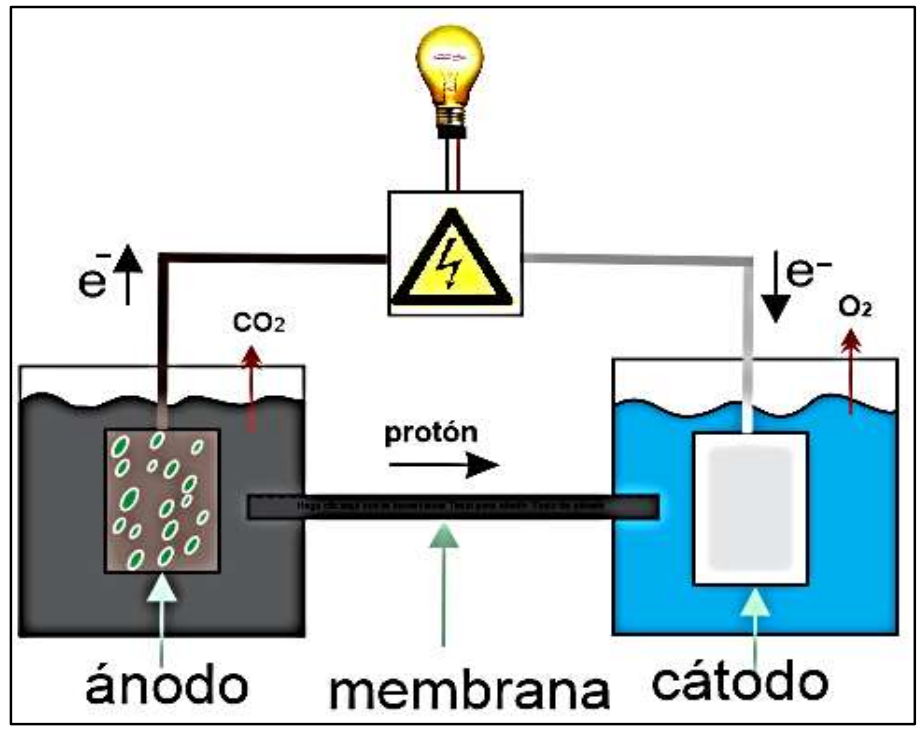

Figura 1: Esquema de la celda de combustible microbiana.
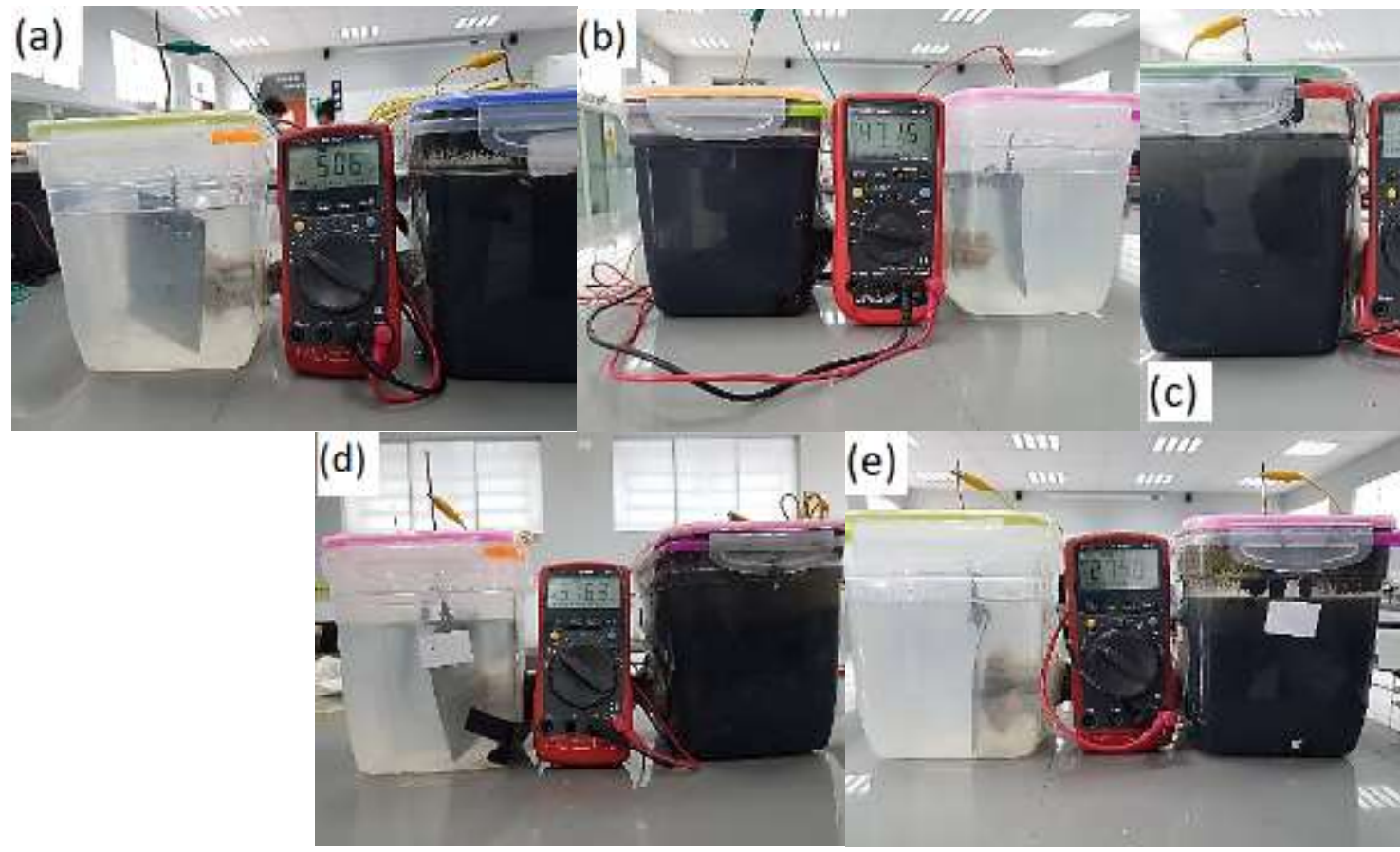

Figura 2: Celdas de combustible microbiano al a)100, b) 90, c) 80 , d) 70 y e) $60 \%$ de lodo.

El voltaje obtenido de las cinco CCM a diferentes concentraciones de lodo (figura 3 ), se puede observar que el voltaje se mantiene casi constante en cada celda, pero a la disminución de lodo el voltaje promedio comienza a disminuir (ver tabla $\mathrm{N}^{\circ}$ 01 ), estos resultados mejoran a los obtenidos por Xiaojing Li (2015). 


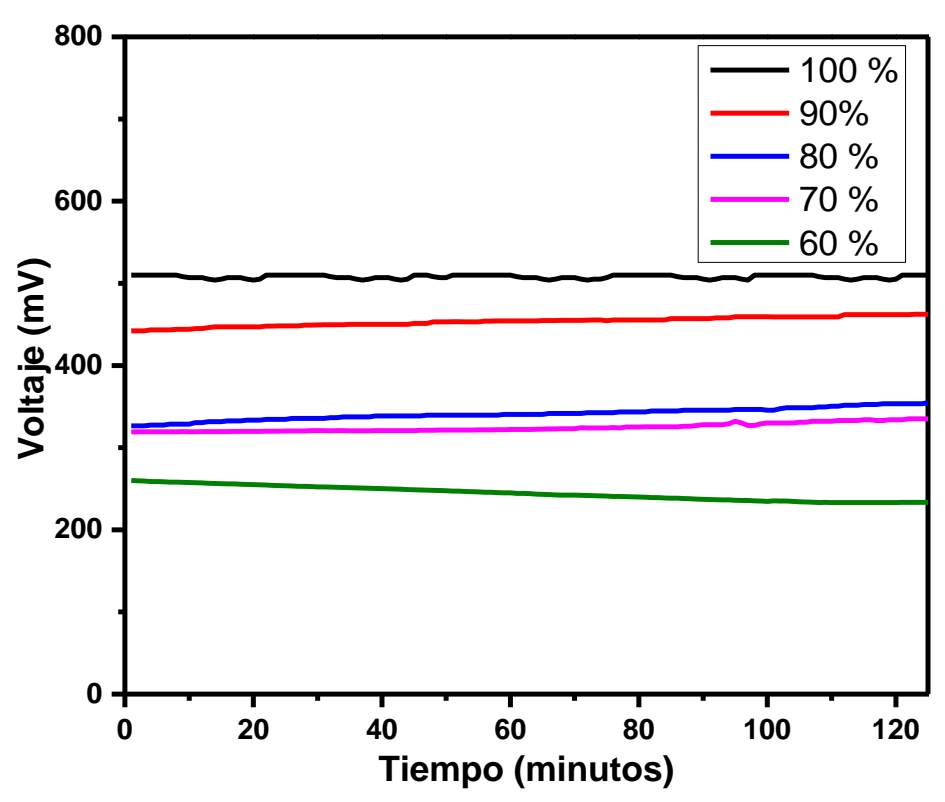

Figura 3: Voltajes obtenidos en las cámaras anódicas de las CCMs a diferentes porcentajes de lodo a través del tiempo.

Tabla 1: Voltaje promedio (Vp), corriente promedio (Ip) y potencia promedio obtenida en las 5 celdas de combustible microbiana.

\begin{tabular}{|l|r|r|r|}
\hline Porcentaje de lodo & $V_{p}(\mathrm{mV})$ & $I_{p}(\mu \mathrm{A})$ & Densidad de potencia $\left(\mathrm{mW} / \mathrm{cm}^{2}\right)$ \\
\hline 100 & 507.8 & 476.7 & 0.24 \\
\hline 90 & 453.9 & 426 & 0.19 \\
\hline 80 & 341.4 & 320.5 & 0.11 \\
\hline 70 & 324.8 & 304.9 & 0.09 \\
\hline 60 & 244.1 & 229.1 & 0.06 \\
\hline
\end{tabular}

Según P. Aelterman, en su investigación "Microbial fuel cells for wastewater treatment", nos dice que un CCM teóricamente (con una eficiencia del $100 \%$ durante el metabolismo) puede entregar $3 \mathrm{Kwh}$ por cada kilogramo de materia orgánica (peso seco) y que durante la conversión de sustrato en CCM, casi ninguna energía se libera en forma de calor externo, y que toda la energía bioquímica en los residuos puede convertirse potencialmente en electricidad. Las intensidades de corriente y potencia también disminuyen, siendo sus valores más altos para el lodo puro (100\%).

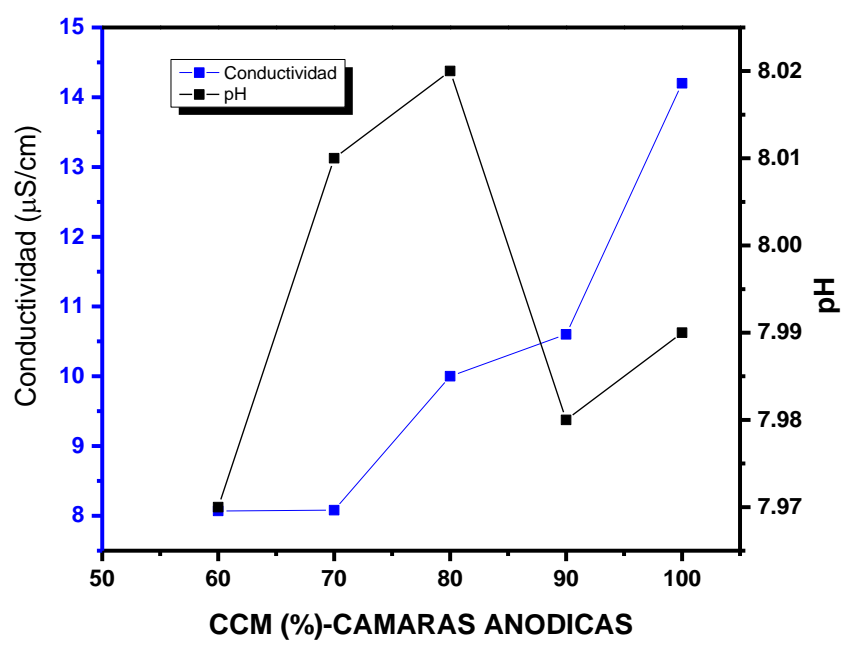


Figura 4: $\mathrm{pH}$ y conductividad en las cámaras anódicas de la CCM a diferentes porcentajes de lodo.

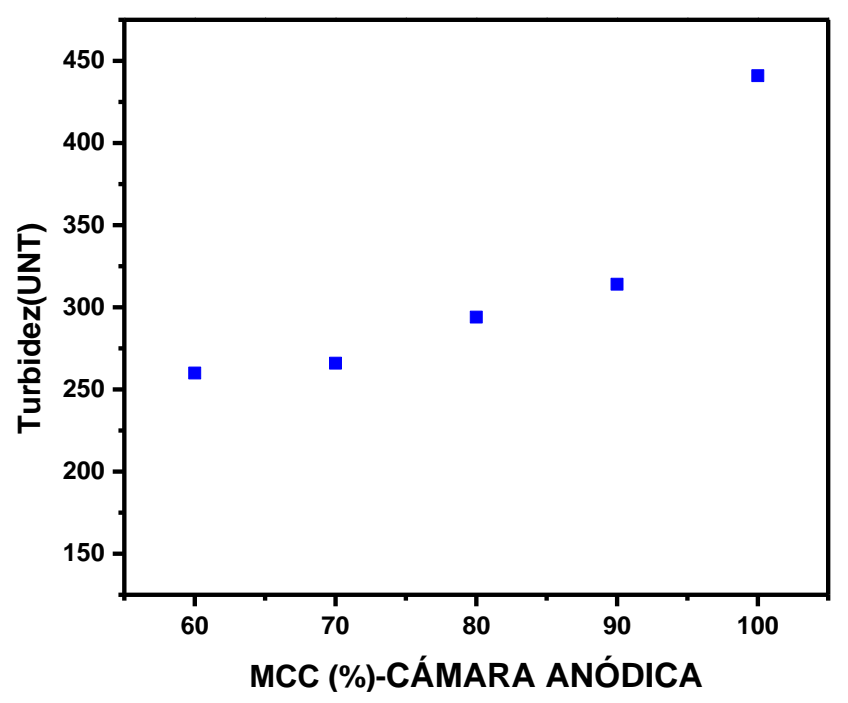

Figura 5: Turbidez de la cámaras anódicas de la CCM a diferentes porcentajes de lodo.

El pH de la cámara anódica se mantiene casi constante alrededor de 8 , mientras que la conductividad decae a la disminución de concentración del lodo (figura 4), según Ruge and Buchi (2001) la conductividad se recomienda que se mayor a $10 \mu \mathrm{S} . \mathrm{cm}^{-1}$, debido a que aumenta las pérdidas ónmicas. Como se puede apreciar en las figuras 5 y 6 la turbidez de la cámara anódica es mucho mayor que en la cámara catódica como era de esperar debido a la cantidad de partículas de suspensión que tienen. En la figura 5 la turbidez comienza a descender debido a que se le disminuyo la cantidad de lodo, mientras que en la figura 6 se mantiene casi constante debido a que a la cámara catódica los parámetros se mantuvieron fijos.

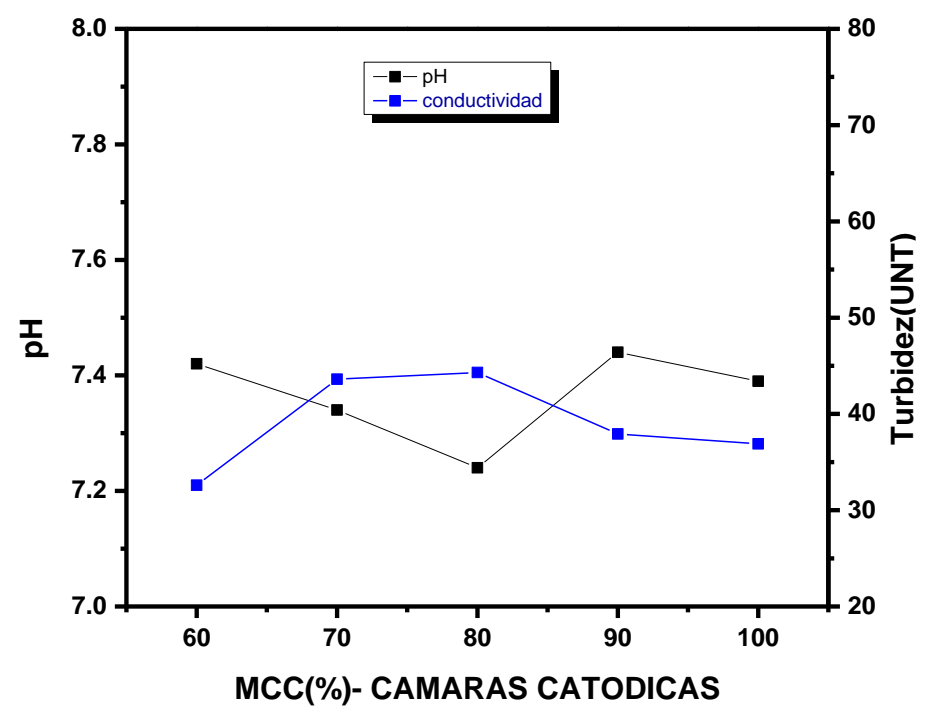

Figura 6: $\mathrm{pH}$ y turbidez de cámara catódica de la CCM a diferentes porcentajes de lodo.

\section{Conclusiones}

En este experimento, se diseñó una celda de combustible microbiana con electrodos baratos (zinc y cobre). La bioelectricidad fue generada exitosamente a partir de lodo usando tecnología de celda de combustible microbiana. El cobre y el zinc se eligieron como el material de electrodo más adecuado y más barato en lugar de grafito, hierro y carbono. El voltaje promedio del circuito fue de $0,507 \mathrm{~V}$ y la corriente de $476,7 \mu \mathrm{A}$, en las demás celdas el voltaje como la corriente fueron disminuyendo. La densidad de potencia máximo fue de $0,24 \mathrm{~mW} / \mathrm{cm}^{2}$. Este tipo de CCM es rentable y 
respetuosa con el medio ambiente debido a la utilización de lodo residual como sustrato. La tecnología de celda de combustible microbiana aún se encuentra en una etapa temprana de desarrollo, pero se muestra muy prometedora como nuevo método para la generación de electricidad renovable.

\section{Referencias}

[1] A. Akella, R. Saini, M. Sharma, Renewable Energy. B 34 (2009) 390-396.

[2] S. P. Goud and N. S. Kothapalli, A novel electricity generation with green technology by Plant-e from living plants and bacteria: A natural solar power from living power plant, Computer Applications In Electrical Engineering-Recent Advances (CERA) 6 (2017) 1-6.

[3] D. Strik, H. Hamelers, J. Snel, and C. Boisman, International Journal of Energy Research 10 (2018) 1-7.

[4] T. Springer, T. Zawodzinski, and S. Gottesfeld, Journal of The Electrochemical Society 138 (1991) 2334-2342.

[5] M. Rahimnejad, A. Adhami, S. Darvari, A. Zirepour, and S. Oh, Alexandria Engineering Journal 54 (2015) 1-12.

[6] F. Scholz and U. Schröder, Nature Biotechnology 21 (2003) 1151-1152.
[7] M. Revelo, H. Hurtado y O. Ruiz, Inf. tecnol. 24 (2013) 17-28.

[8] A. EIMekawy, H. Hegab, D. Pant, and C. Saint, J Appl Microbiol 124 (2018) 302-313.

[9] B. Kim, H. Kim, M. Hyun, and D. Park, Journal of Microbiology and Biotechnology 9 (1999) 127-131.

[10] J. Larminiev and A. Dicks, Fuel Cell Systems Explained (Wiley, England, 2003), 2da Ed., p.121-139.

[11] X. Li, X. Wang, L. Wan, Y. Zhang, N. Li, D. $\mathrm{Li}$, and $\mathrm{Q}$. Zhou, Journal of Chemical Technology \& Biotechnology 91 (2016) 267275.

[12] P. Aelterman, K. Rabaey, P. Clauwaert, and W. Verstraete, Water Science and Technology 54 (2006) 9-15.

[13] M. Ruge, and F. Buchi, Bipolar elements for PE fuel cell stacks based on the mould to size process of carbon polymer mixtures, Proceedings the First European of PEFC Forum 2 (2001) 299-308.

[14] Shripad Revankar and Pradip Majumdar, Fuel Cells: Principles, Design, and Analysis, Tayloe \& Francis Group 1 (2016) 20-60.

Email: segundo.rojas.89@gmail.com 